\title{
Chapter 6 Stakeholders and organization of research reactor safety in France
}

The organization of safety in France has changed over time. While the intention is not to provide a complete history of the organization of safety ${ }^{125}$ in this chapter, some of the aspects most relevant to a publication specifically about research reactor safety are nevertheless worth mentioning.

The organization of safety originally relied on the French Atomic Energy Commission (CEA), which was given responsibility when it was created in 1945 for developing all necessary aspects of the use of this type of energy - in particular by building and operating research reactors. However, a decree was passed in 1973 setting up a special safety body, the SCSIN (Service central de sûreté des installations nucléaires), within the Ministry of Industry. This body underwent a number of changes and had various different names at different times, but it eventually finished up with the creation in 2006 of an independent authority, the French Nuclear Safety Authority (Autorité de sûreté nucléaire, or ASN).

In addition, the part of the CEA concerned particularly with safety and radiological protection research and assessment was turned into a separate institute, the Institute for Protection and Nuclear Safety (IPSN), in 1976. The IPSN is the forerunner of the IRSN, created in 2002, which is now independent of the CEA and includes the Office for Protection against lonizing Radiation (OPRI), previously under the authority of the Ministry of Health.

125. For this, see the work by Philippe Saint Raymond entitled "Une longue marche vers l'indépendance et la transparence - Histoire de l'Autorité de sûreté nucléaire française", La documentation française, 2012. 


\subsection{Operators}

The organization of safety in France - obviously in line with the principles and recommendations issued by international organizations like the IAEA - takes account of specific national factors. France's largest nuclear facilities are operated by large organizations: Électricité de France (EDF) for power reactors, Cogéma, once part of AREVA (now Orano), for most fuel cycle facilities, and the CEA for most research reactors (and other facilities), the exception being the Institut Laue-Langevin (ILL), an international body, which operates the RHF at Grenoble.

French operators are therefore much less fragmented than in most other countries and generally participate in the design of their facilities. They consequently have a particularly high level of expertise. The CEA also has specific scientific and technical expertise in fields related to nuclear safety, particularly through its heavy involvement in research and development programmes in this area.

A fundamental principle, promoted in IAEA documents, is that operators are responsible for the safety of their facilities, because only they can take the practical action that directly influences safety. In French regulations, this principle is set out in the Environment Code (Article L. 593-6): "The operator of a nuclear facility is responsible for controlling the risks and drawbacks presented by its facilities".

However, operators must provide evidence of this to the public authorities responsible for protecting people and property throughout France. This evidence must be provided in the form of binding written documents sent to the ASN, containing the operators' own analyses. Operators may also have to provide any further details or information considered necessary, in an appropriate form, in the context of inspections carried out by the ASN, assessments by IRSN or meetings with the standing groups of experts commissioned by the ASN, or at meetings of local information commissions $\left(\mathrm{CLI}^{126}\right)$ or the national association of local information commissions (ANCCLI $\left.{ }^{127}\right)$.

Moreover, in accordance with the Act on nuclear security and transparency adopted in 2006 (known as the TSN Act - see section 6.2), all operators of basic nuclear installations must produce a report each year stating:

- "the nuclear safety and radiological protection measures taken;

- nuclear safety and radiological protection incidents and accidents subject to the reporting obligation (...) that have occurred at the installation, as well as the measures taken to limit their development and mitigate the consequences for human health and the environment;

- the nature and results of measurements of radioactive and non-radioactive releases from the installation into the environment;

- the nature and quantity of radioactive waste stored at the installation site, and the measures taken to limit the volume and effects of the waste on health and on the environment, especially soil and water".

126. Commission locale d'information in French.

127. Association nationale des comités et commissions locales d'information in French. 
This report is made public and a copy is sent to the local information commission and to the High Committee for Transparency and Information on Nuclear Security (HCTISN ${ }^{128}$ ).

The roles of the ASN, the IRSN and the standing groups of experts are briefly explained in the next section.

\subsection{Control of nuclear risks in France}

As explained in previous chapters, research reactors can vary greatly in terms of utilization, technical characteristics and operating procedures. However, all research reactors are categorized as basic nuclear installations $\left(\mathrm{INB}^{129}\right)$ and are therefore subject to the regulatory requirements applicable to all INBs.

The adoption of Act No 2006-686 of 13 June 2006 on nuclear security and transparency (known as the TSN ${ }^{130} \mathrm{Act}$ ) has been the most significant change in recent years to the institutional and legal framework applicable to basic nuclear installations. Specifically, the TSN Act set up, for civil-related facilities and activities, an independent administrative authority, the French Nuclear Safety Authority (ASN). The Act sets out the general principles governing nuclear activities (in addition to the principle of the operator having prime responsibility, there are other such as the precautionary principle, the preventive action principle, the "polluter pays" principle, etc., which are briefly explained in the focus section below). More recently, the Act on energy transition for green growth (TECV ${ }^{131}$ Act No 2015-992 of 17 August 2015) strengthened some aspects of the TSN Act, particularly as regards transparency and public information, management of subcontracting at INBs, and permanent shutdown and dismantling of INBs.

\section{\#FOCUS \\ The principles of nuclear safety, radiological protection and environmental protection in France ${ }^{132}$}

Nuclear activities must be carried out in compliance with the fundamental principles set out in law and in international standards. In particular:

- in France, the principles set out in the Environmental Charter attached to the Constitution, and in different codes (Environment Code, Public Health Code, etc.);

128. Haut Comité pour la transparence et l'information sur la sécurité nucléaire in French.

129. Installations nucléaires de base in French.

130. Now codified in the French Environment Code.

131. Transition énergétique pour la croissance verte in French.

132. According to the ASN's publication "The principles and stakeholders in nuclear safety regulation, radiation protection and protection of the environment". 
- at European level, the rules defined by directives establishing a Community framework for the safety of nuclear facilities and for the responsible and safe management of spent fuel and radioactive waste;

- at international level, the fundamental safety principles established by the IAEA and implemented under the Convention on Nuclear Safety, which establishes the international framework for nuclear safety regulation and radiological protection.

There is significant overlap between these different measures. They can be summarised in the form of eight principles, as follows:

\section{- Principle of prime responsibility of the operator}

This principle was presented in section 6.1.

- "Polluter pays" principle

The "polluter pays" principle is the adaptation of the principle of prime responsibility of the operator to the terms of the Environment Code, namely that the polluter responsible for environmental damage must bear the cost of measures to prevent and reduce pollution.

- Prevention principle (or principle of preventive action or rectification at source)

The prevention principle requires the implementation of rules and actions to anticipate environmental damage, which must take account of the best available techniques at an economically acceptable cost.

\section{- Participation principle}

The participation principle requires public participation in decision-making by the public authorities; it stems directly from the Aarhus Convention. In the nuclear field, the practical expression of this principle is the organization of national public debates, which are mandatory prior to the construction of a nuclear power plant, for example, and public inquiries, especially during the examination of licence applications to construct or dismantle nuclear facilities.

\section{- Precautionary principle}

Under the precautionary principle, a lack of certainty in view of current scientific and technical knowledge should not delay the adoption of environmental protection measures. It is defined in the Environmental Charter as follows: "Where there is the possibility of severe and irreversible damage to the environment, even though this is not a certainty given the current state of scientific knowledge, the public authorities shall ensure, by applying the precautionary principle in the areas within their remit, that procedures are followed to assess the risks and that provisional, proportionate measures are taken to prevent the damage". As regards the biological effects of small doses of ionizing radiation and low dose rates, the precautionary principle assumes that the relationship between dose and effect is linear, with no threshold. 


\section{- Justification principle}

The Public Health Code states that "a nuclear activity or operation may be performed only if it is justified by the advantages it provides, especially for health, society, the economy, or science, compared to the risks it may pose of exposure of persons to ionizing radiation".

- Optimization principle

The Public Health Code states that "exposure of persons to ionizing radiation resulting from a nuclear activity or operation must be kept to the lowest level that can reasonably be achieved, taking account of technical, economic and social factors, and, where relevant, the medical objective sought". This principle, also known as the ALARA principle, can for example, in the case of discharge permits, lead to the permitted quantities of radionuclides in radioactive effluent discharged by nuclear facilities being reduced, can mean that exposure monitoring at workstations is required to keep exposure to the level strictly necessary, and can mean monitoring is necessary to ensure medical exposure due to diagnostic procedures remains within pre-established reference levels.

- Dose limitation principle

The Public Health Code states that "the exposure of a person to ionizing radiation resulting from a nuclear activity may not cause the sum of received doses to exceed regulatory limits, except when the exposure is for medical or biomedical research purposes". There are strict limits on exposure of the general population or workers due to nuclear activities. These limits include wide safety margins to prevent effects on health. They are also well below the doses for which probabilistic effects (cancer) begin to be observed. Exceeding these limits is considered to be unacceptable. In France it can lead to administrative or criminal sanctions. In the case of medical exposure, no strict dose limit is set since this deliberate exposure is justified by the expected health benefit for the exposed person.

According to Article 1 of the TSN Act, nuclear security encompasses nuclear safety, radiological protection, prevention of and protection from malicious acts, as well as civil protection in the event of an accident. The requirements for basic nuclear installations, from construction to permanent shutdown and dismantling, are laid down by the 2007 "INB procedures" decree ${ }^{133}$ (and the 2016 amending decree ${ }^{134}$ ) and the order of 7 February 2012 setting general rules for basic nuclear installations, known as the "INB" order. This order - which entered into force on 1 July 2013 - has gradually been supplemented by the ASN's regulatory decisions on particular generic issues. These constitute the regulatory basis applicable to all INBs.

133. Decree $N^{\circ} 2007-1557$ of 2 November 2007 on basic nuclear installations and on the control, as regards nuclear security, of the transport of radioactive substances.

134. Decree $\mathrm{N}^{\circ} \mathbf{2 0 1 6 - 8 4 6}$ of 28 June 2016 on the modification, permanent shutdown and dismantling of basic nuclear installations and on subcontracting. 
Between 1980 and 1992, 40 "fundamental safety rules" (RFS ${ }^{135}$ ) were established in France on different topics and different types of INB. The purpose of these rules was to set out the conditions be met by a particular type of facility for it to be considered compliant with French technical regulatory practice, while giving the operator (and the designer) the option of non-compliance if it could justify that the safety objectives were met by other means. Further texts of a similar nature are being produced, known as "ASN Guides "136".

Two fundamental safety rules ${ }^{137}$ specific to research reactors were established in the 1980s and 1990s. They were:

- the fundamental safety rule SIN N C-12308/86 (RR1) of 4 August 1986, on purification equipment in research reactor ventilation systems. Because research reactors are facilities with one or more vessels kept under negative pressure by ventilation circuits providing "dynamic" confinement, the rule sets out a number of recommendations for the implementation of devices to filter and purify the air: high efficiency particulate air (HEPA) filters to trap the aerosols, and iodine filters $\left(\mathrm{PAI}^{138}\right)$ consisting of solid adsorbent materials ${ }^{139}$. These recommendations concern the design, implementation, installation and assembly, efficiency and use of this equipment, especially as regards in-service inspection. In particular the rule states that PAls must be preceded, where relevant, by systems that rapidly reduce the relative humidity of the gases to be purified so that the efficiency of these filters is acceptable at first use.

- the fundamental safety rule SIN No C-12670/91 (RR2) of 1 July 1991 on protection against fire risks at research reactors. ASN Decision No 2014-DC-0417 of 28 January 2014, supplementing the "INB" order, sets out the requirements for controlling fire risks at basic nuclear installations; the safety approach followed by this Decision is explained in section 7.4.1.

\section{\#FOCUS}

\section{Pyramid of official texts applicable in France to basic nuclear installations}

The pyramid of official texts applicable in France to INBs is shown in figure 6.1 below.

- Laws

A law (Act) is a written rule, generally passed by parliament (National Assembly and Senate) following legislative procedure. A law can be

135. Règles fondamentales de sûreté in French.

136. More than thirty ASN Guides were in existence as at mid-2018.

137. "Législation et règlementation, Sûreté nucléaire en France", Les Journaux officiels, May 1999.

138. Pièges à iode in French.

139. Such as activated carbon. 


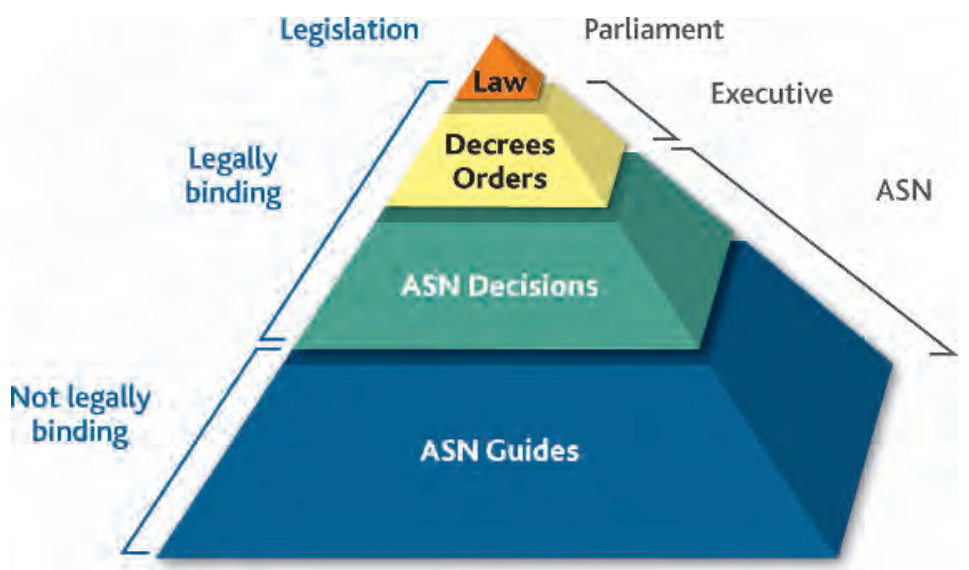

Figure 6.1. Diagram showing the pyramid of official texts applicable to INBs. C) Georges Goué/ IRSN.

adopted on the initiative of parliament (proposition de loi) or of the government (projet de loi). Once it has been promulgated by presidential decree, everyone must abide by it. Before it is promulgated, it may be put through a test of its constitutionality by the Constitutional Council.

- Decrees

A decree is a regulatory act signed either by the French President or by the Prime Minister. Some decrees (décrets en Conseil d'État) can only be enacted after consulting the Conseil d'État. Decrees are often adopted in application of a law. They may be supplemented by ministerial orders.

- Orders

An order (arrêté) is an administrative decision which is either general or specific (to a sector or geographical area) in scope. Orders can be issued by ministers (ministerial or interministerial orders), prefects (prefectoral orders) or mayors (municipal orders).

- ASN Decisions

Act No 2006-686 of 13 June 2006 (TSN Act) lists the different categories of regulatory and individual decisions that the ASN takes, for example:

- regulatory decisions of a technical nature for the application of decrees or orders on nuclear safety and radiological protection,

- commissioning licences for INBs,

- permits and approvals for the transportation of radioactive materials or for medical facilities and equipment using ionizing radiation.

\section{- ASN Guides}

In replacement of the fundamental safety rules, the ASN Guides are documents for use by professionals affected by nuclear safety and 
radiological protection regulations (designers, operators, users or transporters of radioactive materials, health professionals). They aim to:

- explain a regulation and the rights and obligations of persons concerned by the regulation;

- explain the objectives of the regulation and where necessary describe the practices which the ASN considers satisfactory;

- provide practical and useful information on nuclear safety and radiological protection.

The equipment in research reactors may be subject to French regulations on pressure equipment, especially the order of 30 December 2015 on nuclear pressure equipment (known as the "ESPN ${ }^{140 "}$ order). This order lays down a number of requirements, classifying equipment:

- according to levels (three levels, N1, N2 and N3, in descending order of the radioactive emissions that could result from their failure);

- and categories (five categories, 0, I, II, III and IV, in ascending order of other risks, particularly those associated with the volume and pressure of the fluids they contain).

Fixed equipment in research reactors and experimental devices (e.g. pressurized loops) may be subject to the provisions of this order. This will not be discussed further in this report ${ }^{141}$.

As stated earlier, the operator of an INB has prime responsibility for the safety of the facility and must provide evidence that the measures taken to ensure the facility's safety are appropriate (the safety demonstration). This evidence is presented in a set of documents, which are used by the public authorities to decide whether or not to grant licences for the operation of facilities. These documents are:

- the safety report, which describes the facility and specifies the design of its systems, structures and components and existing or planned measures to prevent incidents and accidents and to limit the consequences of any incidents or accidents that do occur;

- the general operating rules ( $R G E^{142}$ ), an operational document setting out the operating procedures, which must be consistent with the evidence presented in the safety report;

140. Équipements sous pression nucléaires in French.

141. However, please see the comprehensive paper in the journal Contrôle No. 186 from 2010, entitled "Les équipements sous pression nucléaires dans les réacteurs de recherche" by F. Koskas, P. Trémodeux, D. Bourguignon, J. Reuchet and D. Acker, CEA. Most equipment items in research reactors subject to the "ESPN" order are classified as N2 or N3.

142. Règles générales d'exploitation in French. 
- the impact study justifying existing or planned measures to limit the impact of normal operation of the facility on the public and the environment;

- the on-site emergency plan (PUI ${ }^{143}$ ), which describes the specific organization, resources and actions to be implemented by the operator in the event of an accident affecting the facility that could cause radioactive substances (or chemicals) to be released into the environment;

- the decommissioning plan, which explains the general measures put in place by the operator with a view to the permanent shutdown and dismantling of the facility.

In addition, the ASN can, under conditions clearly defined by regulatory decision, place specific requirements on the operator related to the safety of the facility, or if there are risks considered to be serious and possibly imminent, it can even suspend ${ }^{144}$ the operation of a facility temporarily on a precautionary basis (for example, a decision $^{145}$ was taken in October 2009 to partially suspend the operation of the plutonium technology facility (ATPu ${ }^{146}$ ) at Cadarache).

The safety documents for INBs produced by the operators are examined by the ASN, which regularly seeks technical advice in this context from IRSN or, for the most important issues, from the standing groups of experts.

\section{IRSN}

Within the French system, IRSN has the status of an industrial and commercial public undertaking (EPIC ${ }^{147}$ ) and its missions are laid down in Decree No 2002-254 of 22 February 2002, then in Decree No 2016-283 of 10 March 2016. The TECV Act mentioned above, which was promulgated on 17 August 2015, laid the foundations of the "dual system" of two independent bodies, the ASN and IRSN, and wrote IRSN's missions into the Environment Code.

IRSN is supervised by the five ministries responsible for the environment, industry, research, defence and health. It is the main expert in nuclear and radiological risks for both civil and defence facilities and activities. It assesses exposure of humans and the environment to ionizing radiation and proposes measures to protect the population in the event of an accident. It contributes to public policy on nuclear safety and on health and environmental protection against ionizing radiation, as it did when the TECV Act was being prepared.

Its nuclear safety expertise is based on scientific and technical knowledge; for this purpose, IRSN devotes significant resources to:

- monitoring and analysing experience feedback from events in France and elsewhere in the world;

143. Plan d'urgence interne in French.

144. In "procedures" decree no. 2007-1557 of 2 November 2007.

145. Decision No. 2009-DC-160 of 14 October 2009.

146. Atelier de technologie du plutonium in French.

147. Établissement public à caractère industriel et commercial in French. 
- studies and research and development ${ }^{148}$, including the development of simulation software.

Research requiring major resources is carried out in collaboration with other partners, in various contexts (national, European, international), sometimes with the involvement of universities or the CNRS.

IRSN employs around 1,700 people of whom 1,200 are general and specialist researchers and experts (in mechanics, criticality and neutronics, thermohydraulics, statistics and probability, fire, earth sciences, medicine, biology, agronomy, metrology, etc.) spread across nine sites.

IRSN also takes part in public debates and seminars organized by local information commissions and by ANCCLI - and by the Information Commission ( $\mathrm{CI}$ ) in the case of defence-related nuclear facilities.

At the request of the relevant authority (ASN, or DSND for defence-related facilities), IRSN examines the files submitted by the operators and gives the authority its opinions and recommendations. IRSN's expertise provides valuable support for decision-making; it finds information corresponding to the best state of technical or scientific knowledge in situations where the decision-maker is confronted with issues for which it cannot immediately provide a response.

In the context of the ASN/IRSN "dual system", the TECV Act placed an obligation on IRSN to publish all its expert opinions immediately, before ASN had stated its position.

IRSN's role has a regulatory context but does not simply amount to verifying compliance with regulations. It consists of providing technical clarity as a result of a technical dialogue with the operators. This clarity is based on its wide-ranging and in-depth technical and scientific knowledge - which comes from experience feedback, studies and research -, detailed analysis of data, and the ability to synthesise different specialist contributions. To give an opinion, different components of an overarching problem need to be taken into account, and sometimes these may at first seem irreconcilable. Through the diversity of its expertise, IRSN is able to integrate these different components in its opinions.

Technical dialogue with operators is essential, partly to confirm IRSN's experts' understanding of the safety and radiological protection issues presented in documents submitted by the operators, and partly to avoid a drift towards the submission of applications with no technical or operational substance. Technical dialogue is also a way of sharing safety concerns with operators.

\section{- Standing groups of experts}

Where required by some safety or radiological protection issues, the ASN relies on the support of advisory committees, set up in 1972 and renewed a number of times,

148. The publication "Current State of Research on Pressurized Water Reactor Safety", Science and Technology Series, IRSN/EDP Sciences, 2017, presents some of the research and development in which IRSN is involved - and has been for more than 40 years in some cases. 
named standing groups of experts. There are eight standing groups ${ }^{149}$ of experts (GPEs), each with its own area of expertise (nuclear reactors [GPR], transport [GPT], laboratories and plants [GPU], radiological protection of workers and the public [GPRAD], radiological protection of health professionals, patients and the public for medical applications of ionizing radiation (including industrial applications and research) [GPMED], waste [GPD], nuclear pressure equipment [GPESPN] and - a new one in 2018 - dismantling [GPDEM]).

The standing group members are appointed on the basis of their individual expertise. They come from universities and expert bodies, particularly IRSN, designers (AREVA-NP then Framatome, etc.), operators (EDF, CEA, AREVA-NC then Orano, etc.) and research bodies (CEA, etc.) in the relevant areas. Since June 2014, the broad representation in these standing groups has been enhanced by the presence of representatives from civil society (members of CLIs, representatives of NGOs, etc.). Each standing group of experts can also seek assistance from anyone (in France or elsewhere) with recognised expertise in specific areas.

For each of the issues dealt with, the standing group of experts' discussions are usually based on assessments conducted in advance by IRSN or by the Nuclear Pressure Equipment Department (DEP ${ }^{150}$ ) in the case of the GPESPN, and presented by them. They formally record the conclusions of their examinations in opinions and recommendations sent to the ASN office that referred the matter to them. The standing groups' opinions to the ASN are made public.

The standing groups of experts to which issues related to research reactors are referred are:

- most often, the standing groups of experts for nuclear reactors (GPR),

- the standing groups of experts for nuclear pressure equipment (GPESPN),

- the standing groups of experts for laboratories and plants (GPU) concerning the overall management of safety and radiological protection within CEA or the permanent shutdown and dismantling of reactors (in association with the GPR).

\subsection{Key stages in the life of a research reactor}

From an administrative point of view, the key stages in the life of a research reactor are similar to those for the power plants in the French fleet. Schematically, these key stages correspond to the following types of licence or prescription ("procedures" decree):

- the initial construction licence issued by decree on the basis of a set of documents including, among other things, an impact study, a preliminary version

149. Groupe permanent d'experts in French of réacteurs (GPR), transport (GPT), usines (GPU), radioprotection des travailleurs et du public (GPRAD), radioprotection dans les applications médicales (GPMED), déchets (GPD, équipements sous pression nucléaire (GPESPN) and démantèlement (GPDEM).

150. Direction des équipements sous pression in French. 
of the safety report, and a risk control report presented in an appropriate form for local consultations and the public inquiry;

- the commissioning licence issued by the ASN on the basis, in particular, of an updated version of the safety report, a summary report of the facility startup tests, etc.;

- the decommissioning "prescription" issued by decree, following a public inquiry, on the basis of a special set of documents including the updated decommissioning plan, the impact study and the updated safety report and general surveillance and maintenance rules $\left(\operatorname{RGSE}^{151}\right)$.

Because substantial modifications may be made to the design or utilization of a research reactor during its operating life (e.g. new experimental programmes), specific licences may be necessary, possibly including amendments by decree to the original construction licence decree.

These substantial modifications may cause the research reactor to spend periods on "standby". Under French regulations, a new licence issued by decree is required if the operation of an INB is interrupted for more than two years ${ }^{152}$. Special requirements may be imposed for periods on standby, such as the requirement for a minimum number of personnel to be present to carry out appropriate surveillance, and periodic tests and inspections at suitable frequencies.

For new INBs, the submission of a "safety options report" has become common practice. In the case of research reactors, it can apply not only to new reactor projects (e.g. the Jules Horowitz reactor) but also to large-scale modifications to reactors in service (such as the renewal of the CABRI reactor with installation of the pressurized water loop).

Finally, the obligation to carry out periodic safety reviews of their facilities (in practice every 10 years), stipulated in the TSN Act, applies to research reactor operators. From the point of view of documentation, there are two major milestones in a periodic safety review, involving not only the operator, but also the ASN and experts (IRSN, advisory committees):

- the submission by the operator of a safety review preparation file specifying the perimeter and scale of the compliance review and safety reassessment that it plans to carry out (see section 9.2);

- once the examinations and the safety reassessment studies are complete, the submission by the operator of a report presenting its conclusions including, where necessary, the changes it plans to make in order to improve safety at the facility.

151. Règles générales de surveillance et d'entretien in French.

152. However, as a result of the adoption of the TECV Act No 2015-992 of 17 August 2015, Article L 593-24 of the Environment Code states that "if a basic nuclear installation ceases to operate for a continuous period of more than two years, it is deemed to have been permanently shut down, but the minister responsible for nuclear safety may, at the operator's request, extend this twoyear period by a maximum of three years, by means of an order explaining the grounds for this extension, having first sought the ASN's opinion. At the end of the period stipulated in the first paragraph of this Article, the facility operator is no longer permitted to operate the facility...". 


\subsection{Internal licensing scheme}

Decree No 2007-1557 of 2 November 2007 (the "procedures" decree) introduced the possibility for INB operators to set up an internal licensing scheme enabling them to dispense with reporting to the ASN some minor modifications to their facilities or their general operating rules. The operator must make an application to do this, showing that it has an internal control system and presenting sufficient guarantees of quality, independence and transparency, and must obtain the ASN's approval for the scheme, specifying:

- the type of modifications or operations to be handled in this way;

- the process used to approve the operations, in particular with automatic notification, prior to any operation, of a body that is independent of the persons in charge of the operation;

- the identities of the persons authorised to issue internal licences;

- the procedures for periodically reporting to the ASN on the operations planned or performed.

The requirements applicable to a scheme of this kind were subsequently clarified by the ASN in 2008 in its Decision No. 2008-DC-0106 of 11 July 2008.

For example, the internal licensing scheme proposed by the CEA was approved in 2010. The corresponding decision ${ }^{153}$ listed the INBs concerned, the type of modifications that could not be licensed internally, and the criteria to be met for a modification to be eligible for internal licensing. Most of the CEA's research reactors are on the list of facilities for which the internal licensing scheme approved in 2010 can be used.

As part of this, the CEA sends the ASN, every six months, a provisional programme of operations likely to be internally licensed in the coming year, giving its justification for the approval of these operations by the internal licensing scheme. These programmes are examined by IRSN, which can express reservations to the ASN regarding the rationale for using the internal licensing scheme or regarding the measures planned by the operator in question.

More recently, Decree $n^{\circ} 2016-846$ of 28 June 2016, which amends several aspects of the "procedures" decree (modification, permanent shutdown and dismantling of INBs, use of subcontracting), introduced two regimes for all INB operators:

- a "reporting regime" for minor modifications (obviously ones that do not have an impact on the safety report or the impact study for the facility), a list of which is given in an ASN decision, taking account of the type of facility and the scale of the risks and drawbacks it presents, the operator's technical capabilities and the internal control measures it has implemented in preparation for these modifications;

- a "licensing regime" for other modifications.

153. ASN Decision No. 2010-DC-0178 of 16 March 2010. 
